\title{
Response Analysis of an RC Cooling Tower Under Seismic and Windstorm Effects
}

D. Makovička

The paper compares the RC structure of a cooling tower unit under seismic loads and under strong wind loads. The calculated values of the envelopes of the displacements and the internal forces due to seismic loading states are compared with the envelopes of the loading states due to the dead, operational and live loads, wind and temperature actions. The seismic effect takes into account the seismic area of ground motion $0.3 \mathrm{~g}$ and the ductility properties of a relatively rigid structure. The ductility is assessed as the reduction in seismic load. In this case the actions of wind pressure are higher than the seismicity effect under ductility correction. The seismic effects, taking into account the ductility properties of the structure, are lower than the actions of the wind pressure. The other static loads, especially temperature action due to the environment and surface insulation are very important for the design of the structure.

Keywords: cooling tower, wind load, earthquake, ductility, dynamic response.

This text was a part of the Intenational conference on Advanced Engineering Design (AED 2006), which was held in Prague in 2006.

\section{Introduction}

The objective of this paper is to calculate the basic static and dynamic loading of twin cooling towers with fans $6 \mathrm{~m}$ in propeller diameter for an oil refinery. The basic static and dynamic analyses are based on the requirements of American design standards [1]. The size of the structure was designed to limit the combined static loading states including the actions of wind pressure. The designed quantities due to the action of seismic load in introduction the ductility of the structure are lower than the actions of the wind pressure. The design loads are compared and the dominance of particular loading states is assessed according to the internal force response caused by these loads in the structure. This comparison explicitly shows that the temperature effects exert the biggest influence upon the structure of the towers in the resultant combined design load. The share of these temperature effects in the total stress of the structure can be estimated as approx. $50 \%$.

\section{Description of the structure}

The subject of the analyses is a pair of reinforced-concrete cooling towers located next to each other on a common base plate. Each cooling tower has a square plan. The cooling tower is terminated from above by a floor (ceiling) plate with a circular opening, over which a cylindrical diffuser is located. The cooling towers are arranged in series in such a way that the towers have a common internal wall dividing them all along their height. On the edges of the twin towers, in the longitudinal direction, the transversal external walls are reinforced by three vertical reinforcing ribs of longitudinal orientation. These longitudinal stiffeners $400 \mathrm{~mm}$ in thickness exceed the external surface of the transversal external wall by $1500 \mathrm{~mm}$. The transversal external and internal walls $250 \mathrm{~mm}$ in thickness exceed the external surface of the longitudinal walls by $800 \mathrm{~mm}$. In addition, there are internal stiffeners in the central section of the transversal external walls to reinforce each tower. In the centre of the towers there are columns with fans on them at the level of the ceilings. The columns are strutted in two of their altitudinal levels to the external walls by means of concrete girders, and at the level of the fans by means of steel pipes into the ceiling plates. The longitudinal external walls of the towers, in which there are suction inlets, are reinforced by vertical ribs and horizontal beams flanging the suction inlets. The basic altitudinal level of the structural model +0.0 corresponds with the centre line of the base plate. A spatial computational model of the twin towers was created for these calculations of the cooling towers. The space and the basic dimensions are given in Fig. 1.

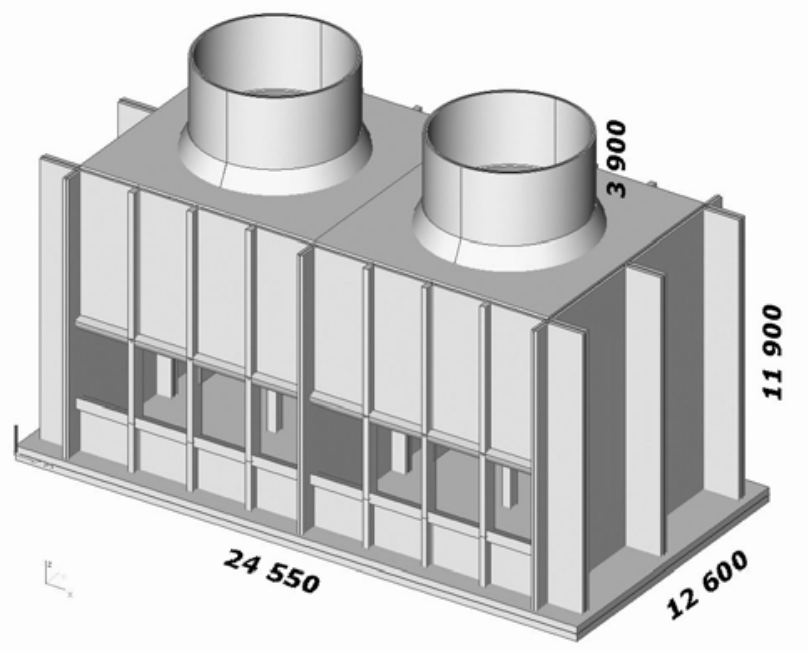

Fig. 1: Basic dimensions of the twin cooling tower unit

The twin cooling towers were designed for the use of Grade 25 concrete (equivalent to concrete class B30). The reinforcement used concrete Grade 400 (equivalent to reinforcement $10425 \mathrm{~V}$ ). The stiffeners and the supporting structure for the technology inside the tower were designed for the use of ASTM A36 steel or similar, (equivalent to steel of series 37). The external walls, the internal wall, the floor plates, the diffuser and the vertical stiffeners were modelled by plate elements corresponding in thickness with the modelled part of the structure. The internal columns, the internal girders, the columns/ribs in the external walls, the horizontal 
reinforcement of the longitudinal walls over and under the shutter opening and the horizontal stiffeners of the fan were modelled by beam elements. The damping used for the dynamic loading states was $5 \%$ of critical damping.

In the computational model, the baseplate was supported by a Winkler-Pasternak sub-base model. The sub-base parameters are automatically determined by the computational program according to the set sub-base structure in the test pits. The starting values of the Winkler-Pasternak constants were selected as follows: $\mathrm{C}_{1 \mathrm{z}}=3.5 \mathrm{MN} / \mathrm{m}^{3}, \mathrm{C}_{1 \mathrm{x}}=\mathrm{C}_{1 \mathrm{y}}=2.0$ $\mathrm{MN} / \mathrm{m}^{3}, \mathrm{C}_{2 \mathrm{x}}=\mathrm{C}_{2 \mathrm{y}}=50 \mathrm{MN} / \mathrm{m}$.

The calculation of improved values for the combined of dead and operational loads is shown in Fig. 2. The baseplate can turn slightly on the sub-base around it's horizontal axes and can shift in the vertical direction. There can be no horizontal shifting of the structure as a whole, i.e. on one longitudinal and one transversal edge of the baseplate. Horizontal shifting on opposite edges is enabled in order to allow thermal expansion of the plate.

\section{Load}

The structure model was loaded with static and dynamic loads. The static loads include the dead weight and the permanent load due to the process equipment, the live load, the operational load, temperature effects and actions of wind pressure. The dynamic loads include the effects due to the fans of the cooling towers and seismic effects.

\subsection{Temperature load due to the environment}

The operating temperature of the towers will comply with the temperature in the period of construction. The external walls, ceiling plates and diffuser are loaded with the non-uniform change in the surface temperature due to a decrease or increase in the ambient air temperature. The columns/ribs in the longitudinal external walls and the external stiffeners of the walls were loaded with the temperature corresponding with the centre line of the wall. The temperature of the internal columns and is unaffected by temperature fluctuations in the operation process; therefore these members are left without temperature load. The internal stiffeners and the diaphragm beam are subject to temperature load only at their edges, where they contact the external walls and ceiling. In these parts, contact sections $725 \mathrm{~mm}$ in width are modelled, being loaded with the temperature corresponding with the centre line of the wall or ceiling.

The environment temperature was adopted from national documents. The temperatures of the surface of the structure were determined in compliance with the theory of heat propagation through a solid medium. The temperature loads were only considered on the part of the structure above the formation level:

- estimated mean temperature of the structure during construction $\quad t_{0}=+35.0^{\circ} \mathrm{C}$,

- normal air operating temperature inside the structure

$$
t_{\mathrm{i}}=+35.0^{\circ} \mathrm{C} \text {, }
$$

- minimum ambient air temperature in the winter period

$$
t_{\mathrm{e}}=-5.0^{\circ} \mathrm{C} \text {, }
$$

- maximum ambient air temperature in the summer period

$$
t_{\mathrm{e}}=+55.0^{\circ} \mathrm{C} \text {. }
$$

This group of temperature loads includes: the non-uniform decrease in the temperature of the surfaces in the winter period, the non-uniform increase in the temperature of the surfaces in the summer period, surface insolation in the perpendicular direction (for ceilings only), and the inclined surface insolation under the incidence of sunbeams at an angle of $45^{\circ}$.
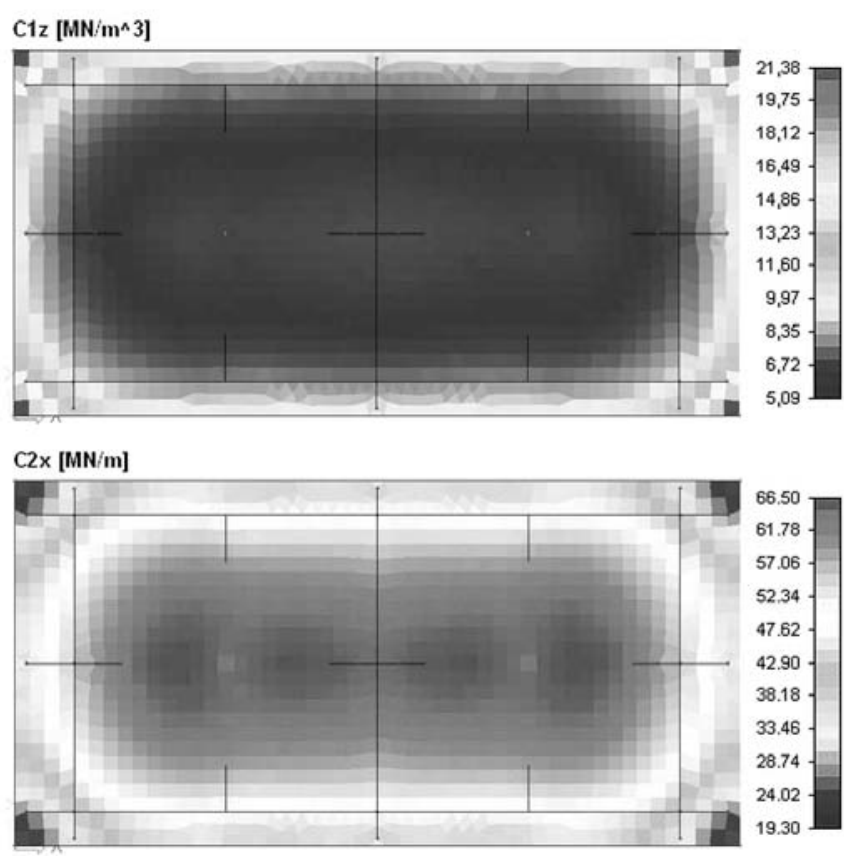

Fig. 2: Winkler-Pasternak factors of the elastic foundation

\subsection{Wind load}

The basic wind pressure values were adopted from [1], and the methodology for determining the load including the elevation effect was adopted from [10]:
- Basic Wind Velocity $V=50 \mathrm{~m} / \mathrm{s}$,
- Topography Factor $S 1=1.0$,
- Wind Pressure Variation with Height
- Statistical Factor $S 2=0.99($ for $h<15 \mathrm{~m})$,
- Design Wind Velocity $S 3=1.0$,
Dynamic Wind Pressure $q=0.613 \times 49.52=1.502 \mathrm{kPa}$.

\subsection{Earthquake load}

The seismic load parameters were determined according to [1] and [9]. According to [9] para 1631.2.5, the vertical acceleration component in comparison with the horizontal component is determined by a coefficient of 0.667 . According to [9] par 1631.4.1, the design elastic response spectrum is:

- Coefficient of significance $\quad I=1.25$,

- Seismic area 1 ,

- Coefficient of seismic area $\quad Z=0.075$,

- Earth medium profile $\quad S_{\mathrm{D}}$ and corresponding,

- Seismic wave propagation velocity (according to [9]) $v_{\mathrm{s}}=360 \mathrm{~m} / \mathrm{s}$,

- Seismic coefficient $\quad \mathrm{C}_{\mathrm{v}}=0.18, \mathrm{C}_{\mathrm{a}}=0.12$, 
- Damping ratio (according to [9] par 1631.2.2)

$$
D=5 \% \text {, }
$$

- Maximum acceleration at the level of the foundation plate

$$
2.5 \times \mathrm{C}_{\mathrm{v}}=0.3 \mathrm{~g} .
$$

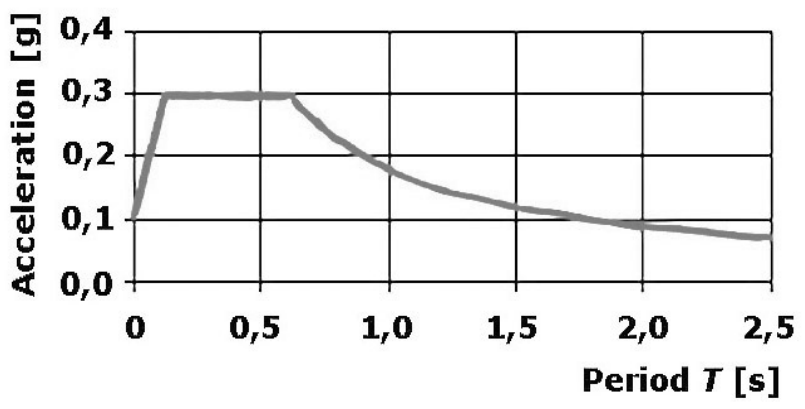

Fig. 3: Design elastic response spectrum

\section{Natural vibration}

For the analyses of the response pf the dynamic structure to seismic load, it is necessary to know the tuning of the structural system. For these purposes, the natural vibration was calculated - calculation of the lowest 100 natural modes of vibration and the equivalent natural frequencies in the frequency interval from approx. $0 \mathrm{~Hz}$ to $50 \mathrm{~Hz}$. This separation is sufficient, as seismic excitation has substantial components approx. up to $32 \mathrm{~Hz}$.

The lowest natural frequency and its modes approx. up to $20 \mathrm{~Hz}$ are important for determining the seismic response of the structure; the influence of the higher modes in determining the total seismic response is very small due to the variable nature of these higher modes (above $20 \mathrm{~Hz}$ approx, the influence is in units or tenths per cent of the total response);

\begin{tabular}{|c|c|c|}
\hline (i) & $f(i)$ & Dominant vibrating part \\
\hline 1 & 2.19 & $\begin{array}{l}\text { Rotating vibration of both towers around } \\
\text { axis } x\end{array}$ \\
\hline 2 & 2.57 & $\begin{array}{l}\text { Rotating vibration of both towers around } \\
\text { axis } y\end{array}$ \\
\hline 3 & 3.28 & $\begin{array}{l}\text { Sliding vibration of towers on the subbase } \\
\text { in the direction of axis } z\end{array}$ \\
\hline 4 & 3.31 & Torsional vibration of walls around axis $z$ \\
\hline 5 & 4.95 & $\begin{array}{l}\text { Higher bending mode of rotating vibra- } \\
\text { tion around axis } x\end{array}$ \\
\hline 6 & 5.25 & $\begin{array}{l}\text { Higher bending mode of rotating vibra- } \\
\text { tion around axis } y\end{array}$ \\
\hline 7 & 11.81 & Bending vibration of longitudinal walls \\
\hline 8 & 12.22 & $\begin{array}{l}\text { Higher mode of bending vibration of lon- } \\
\text { gitudinal walls }\end{array}$ \\
\hline 9 & 13.48 & Bending vibration of transversal walls \\
\hline 10 & 14.19 & $\begin{array}{l}\text { Bending vibration of lower cross and lon- } \\
\text { gitudinal walls }\end{array}$ \\
\hline 11 & 18.62 & $\begin{array}{l}\text { Higher mode of bending vibration of } \\
\text { lower cross and tranversal walls }\end{array}$ \\
\hline 12 & 20.85 & Torsional vibration of beam crosses \\
\hline
\end{tabular}

Table 1 Natural frequencies of vibration $[\mathrm{Hz}]$

approx. from frequencies above $30 \mathrm{~Hz}$ their influence on the total seismic response is even lower. A description of the 12 lowest natural modes of vibration is included in Table 1.

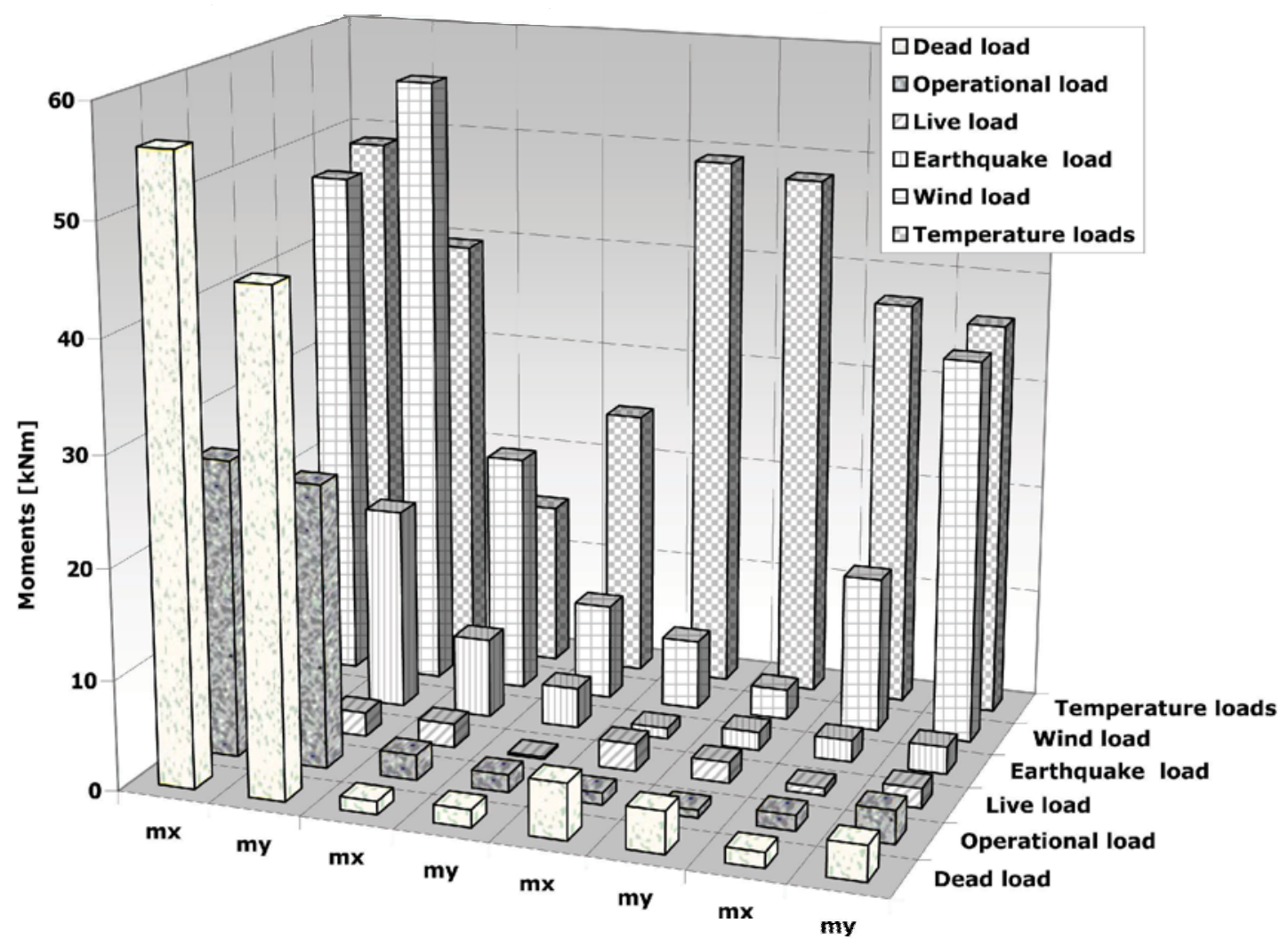

Fig. 4: Comparison of design moments in plate elements for individual groups of loads 


\section{Structural response}

The seismic responses were analysed by means of seismic load decomposition into natural modes of vibration (dynamic modal analysis, according to [2]). Seismic analyses were executed for both horizontal directions $x$ and $y$ of the load action, taking into account the vertical composite action of the seismic excitation (ground motion in direction $z$ ) according to [2] para 1631.2.5. The envelope of the response values was formed on the basis of a seismic combination of these two dynamic analysis states within seismic combination. The analyses of the response on the structure to the seismic load determined the envelope of displacements and internal forces equivalent to the maximum and minimum branch of the envelope of the two load effects in directions $x+z$ and $y+z$. When sizing the structure, it is allowable to reduce the earthquake load by the coefficient of ductility $R$ according to the American standard (according to para 1631.5.4 [2]), which for cooling towers (according to Tab. $16 \mathrm{P}$ in [2]) is determined $R=3.6$. The calculated values of the envelopes of the displacements and internal forces due to the seismic loading states were compared with the envelope of the other loading states due to the dead, operational and live loads, wind and temperature actions (Figs. 4, 5, 6). The seismic effects, taking into account the ductility properties of the structure, are lower than the actions of wind pressure and the rest of the static load, especially temperature action due to the environment and surface insolation.

Note: When reducing the earthquake load by ductility $R$, it is necessary to satisfy the condition of reasonable - sufficient size of the shear reinforcement and the spatial bending rein- forcement, e.g., with a double-sided stressed reinforcement (into the armour plate cross) on both surfaces.

The results of the response are determined in quantities (terms???) of displacements and internal forces. The two characteristics are given separately for the maximum and minimum branch of the envelope of the relevant combination. In order to represent the results of the calculated response clearly, the structure was divided into particular parts of plate elements and beam elements. The particular results are correlated with the coordinate systems, as follows. The internal forces in plate elements, i.e. moments $m_{x}$ and $m_{y}$, and axial forces $n_{x}$ and $n_{y}$, are determined in the middle plane of the plates, and they are correlated with the local axes of the plate elements. In the vertical members (in the walls, stiffeners and diffuser) local axis $x$ has a horizontal (global) direction, local axis $y$ has a vertical (global) direction. Local axis $z$ has the direction normal to the middle plane of the element; the internal forces in the horizontal structures (ceilings, baseplate) have local axes $x$ and $y$ parallel to the global axes. Axis $z$ is normal to the centre line of the member, and it is directed upwards. In the beam elements, local axis $x$ is the axis of the centre line of the member; axes $z$ and $y$ are the axes of the cross section through the beam member. Axis $z$ is as a rule the axis in the direction of a longer dimension (height) of the section.

\section{Conclusion}

Using the example of a cooling tower unit, this paper analyses the influence of wind and natural seismicity and temperature effects beyond the usual static load (dead, operational and live loads) on the static and dynamic response, and

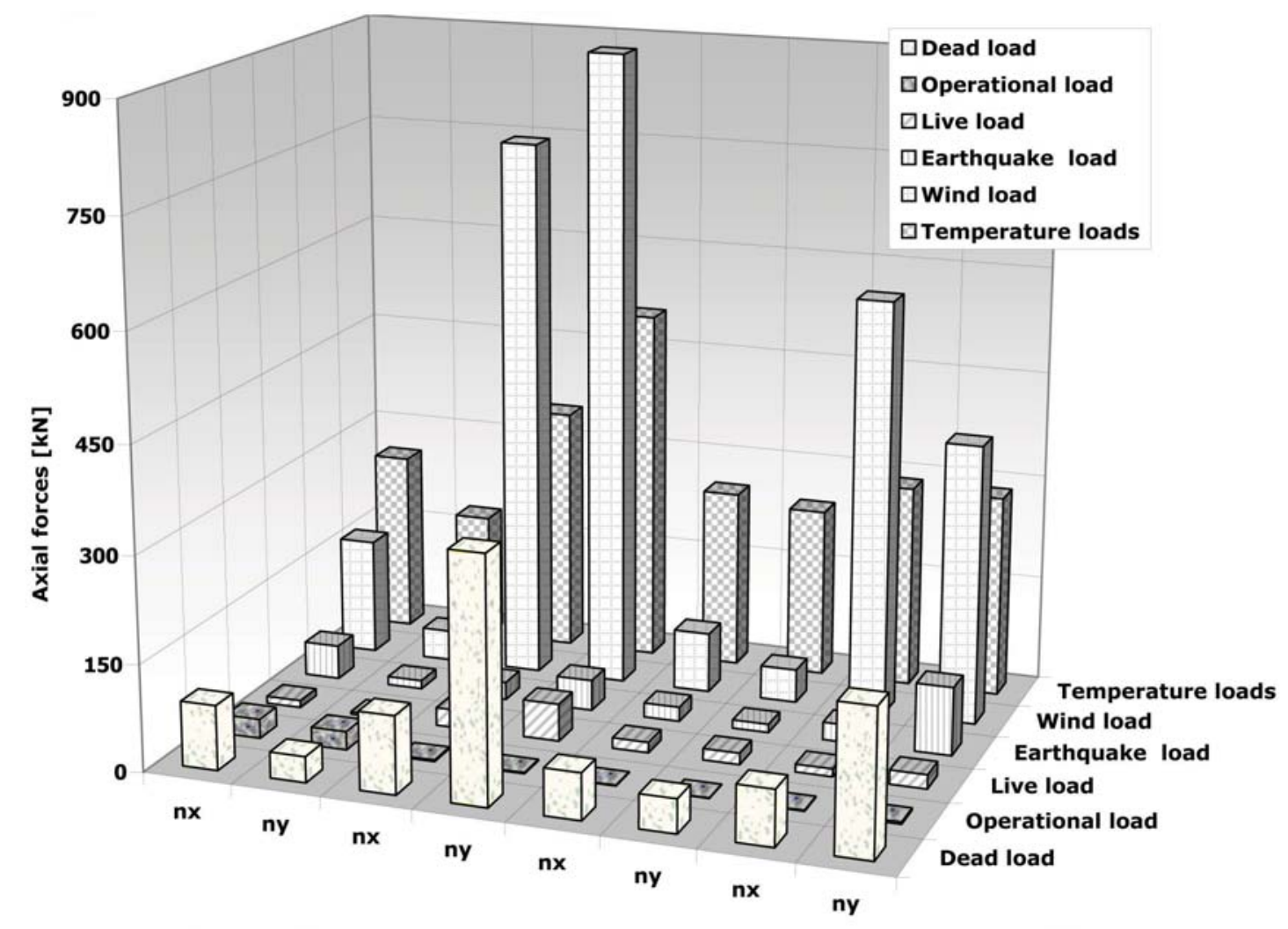

Fig. 5: Comparison of design axial forces in plate elements for individual groups of loads 


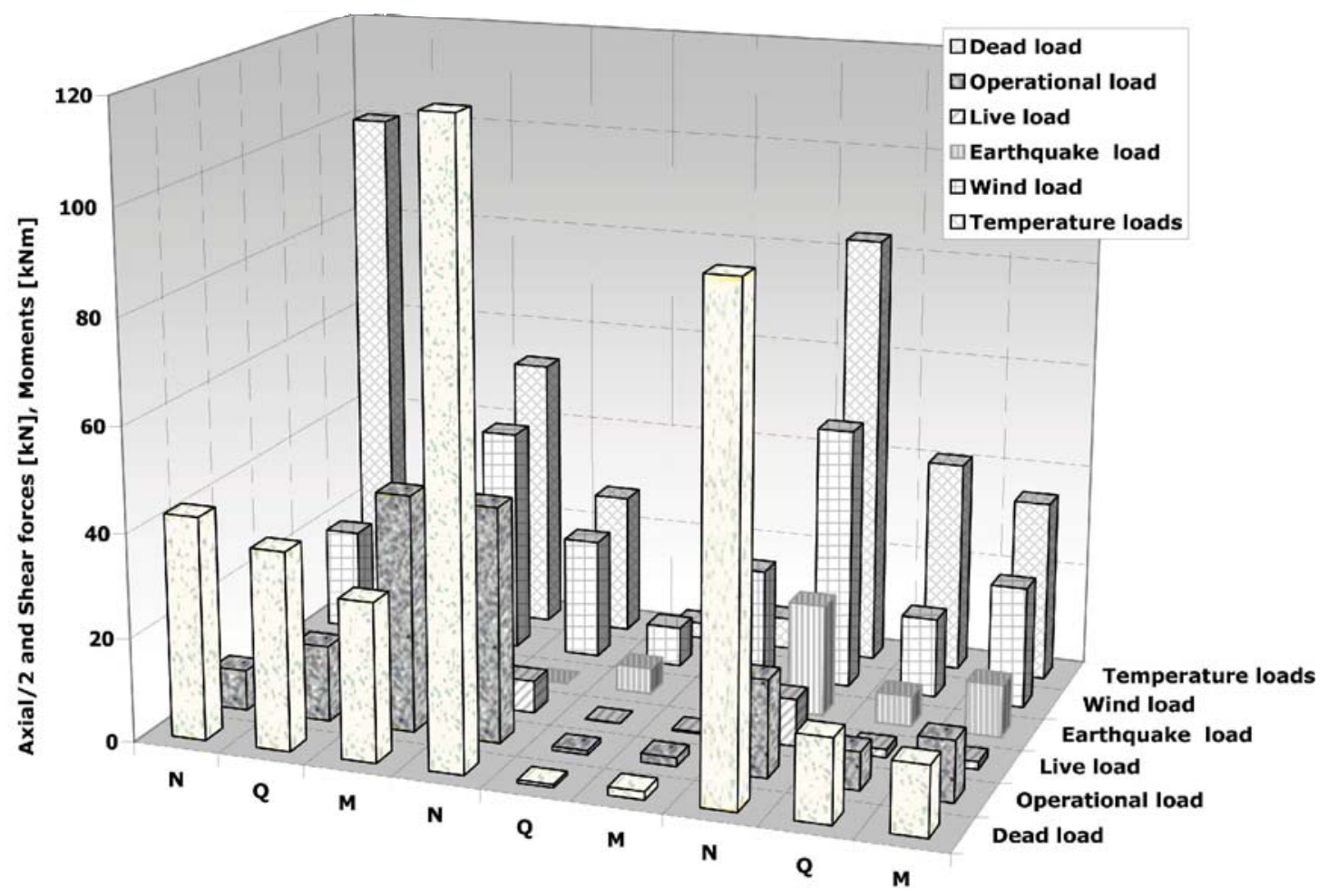

Fig. 6: Comparison of the design axial and shear forces and the moments in the beam elements for individual groups of loads

it compares the significance of these load types for the safety and reliability of the structure. The comparison has revealed that the dominant effect on the structure with reference to its safety (maximum displacements, extreme stress state in selected cross sections, etc.) is exercised by the temperature effect together with the design wind load. The effects of natural seismicity (without reducing of this load by ductility factor $R$ ) are comparable with the dynamic wind load within the interval of the design wind velocities. However, technical seismicity may become dominant for the reliability of the structure when there is vibration of selected parts, such as joints, measuring probes installed in the structure for technological purposes, etc.

For structural design, the static loads were combined with the wind effect. The wind effect is greater than the reduced seismic load. The reinforced concrete structure of the towers must also have sufficient reserves for ductility strain at seismic load. In order to enable this ductility strain, the structure must be appropriately reinforced, especially by a shear reinforcement - the principles of reinforcement are given in the Standard [4]. When using the ductility factor for sizing the dimensions of the structure, it must be submitted (Acknowledged, or - taken into account??) that after an earthquake the structure will be damaged and must be repaired (ductility strain assumes the occurrence of cracks). The internal process equipment inside the towers will probably need to be replaced.

\section{Acknowledgment}

This paper was supported as a part of the research projects in GAC̆R No. 103/03/0082 "Nonlinear response of structures under extraordinary loads and man-induced actions" and GAČR
No. 103/06/1521 "Reliability and risks of structures in extreme conditions", for which the authors would like to thank the Agency.

\section{References}

[1] ANSI/ASCE 7-95: Minimum Design Loads for Buildings and Other Structures.

[2] UBC 1997: Uniform Building Code-Volume 2, Division IV - Earthquake Design.

[3] BS CP3:C5, P2: Basic data for the design of buildings. Chapter V. - Loading, Part 2. Wind loads.

[4] Building Code Requirements for Structural Concrete (ACI 318M-02) and Commentary (ACI 318RM-02), metric version.

[5] Eurocode 2: Design of Concrete Structures. EN 1992, December 2004.

[6] Makovička, D.: Ductile Behaviour of Dynamically Loaded Structures. In: EURODYN '99, A. A. Balkema, Rotterdam, 1999, p. 1136-1140.

[7] Makovička, D., Makovička, D.: Assessment of the Seismic Resistance of a Ventilation Stack on a Reactor Building, Nuclear Engineering and Design, Vol. 235 (2005), Elsevier B.V., p. 1325-1334.

[8] Makovička, D., Makovička, D.: Ductile Characteristics of RC Structures under Seismic Effects (in Czech), Beton 2005, No. 9, p.42-47.

Doc. Ing. Daniel Makovička, DrSc.

Klokner Institute

Czech Technical University in Prague

Šolínova 7

16608 Praha 6, Czech Republic 